\title{
Un ministerio para la ciencia y la tecnología ${ }^{1}$
}

\author{
Todavía falta un trecho para que el ministerio se haga realidad, pero se dio \\ un paso positivo
}

Moisés Wasserman

En medio de la abrumadora dinámica política de los últimos días, pasó casi desapercibida la aprobación en la Cámara de Representantes de un proyecto de ley para la creación del Ministerio de Ciencia, Tecnología e Innovación. Dos representantes liberales antioqueños, Iván Darío Agudelo y John Jairo Roldán, asumieron el proyecto como su tarea, y fue aprobado por unanimidad a pesar de no ser bandera de gobierno ni de partido (¿o tal vez por eso?).

Todavía falta un trecho para que el ministerio se haga realidad, pero se dio un paso positivo. No es una idea nueva; se deriva de la historia de nuestra ciencia, tan alabada de labios para afuera, tan abandonada en la realidad. La primera ley de ciencia y tecnología (29 de 1990) trasladó a Colciencias del Ministerio de Educación Nacional al Departamento Nacional de Planeación, reconociendo que la $\mathrm{C}$ y $\mathrm{T}$ no eran solo un asunto educativo, sino que tenían una importancia transversal en el Estado.

Pero la presencia de Colciencias en Planeación no tuvo la relevancia que esperaban los legisladores. Así, la segunda ley de C y T (1286 de 2009) la convirtió en un departamento administrativo adscrito a la Presidencia de la República. Se planteó inicialmente que fuera un ministerio, pero quienes lideraban la iniciativa se transaron por esa figura, que teóricamente le daba la posibilidad de ser invitada al consejo de ministros y le otorgaba una cercanía natural con el Presidente. Infortunadamente esos hechos no se concretaron, y Colciencias siguió estando alejada de los círculos de decisión.

Se ha reflexionado en la academia sobre los motivos del bajo interés de los gobiernos colombianos por la ciencia. Hay muchas explicaciones, creo que las razones culturales no son menores. Nuestros gobernantes y líderes, en el fondo de su alma, y sin reconocerlo explícitamente, han creído que eso de generar conocimiento no es un oficio para nosotros ("que inventen los ingleses") y que siempre podremos comprar la tecnología y la innovación que necesitemos para mejorar nuestra productividad y competitividad. Hoy es bastante claro lo equivocados que han estado.

La verdad es que ni siquiera la comunidad académica tiene una posición única sobre la bondad de un ministerio. Hay muchas formas para hacer las cosas bien. Hay países que tienen ministerios de ciencia que han generado un cambio radical, como Brasil. En Chile se acaba de crear, por unanimidad, en un proceso en el que participaron dos gobiernos opuestos y todos los partidos, el Ministerio de Ciencia, Tecnología, Innovación y Conocimiento. En España funcionó durante muchos años. El gobierno de Rajoy trasladó sus competencias al Ministerio de Economía, pero apenas la semana pasada el nuevo gobierno lo restauró y puso en su cabeza al astronauta español (se puede decir que apuntan alto). Pero hay muchos países que han desarrollado excelentes sistemas científicos

1 Columna publicada el 15 de junio 2018 en el diario El Tiempo, http://www.eltiempo.com/opinion/columnistas/ moises-wasserman/un-ministerio-para-la-ciencia-y-la-tecnologia-230572 
sin un ministerio (aunque siempre con una institucionalidad muy sólida).

El temor de algunos académicos es que el ministerio se politice y se vuelva un botín. El proyecto de ley contempla también la formación de un consejo nacional de altísimo nivel, con participación de varios ministerios y representación amplia de la sociedad civil. Las objeciones que se le hacen es que el consejo es de tan alto nivel que posiblemente no se pueda reunir.

Pensamos en forma extraña. Sentimos que los cuerpos políticos no funcionan por ser políticos, entonces hay que protegerlos de la política, y que los consejos de alto nivel no funcionan precisamente por ser de tan alto nivel. ¿No será que vale la pena arriesgarse y diseñar un ministerio pensando que va a funcionar? La ciencia mejorará su posición; de los ajustes nos ocuparemos después. 


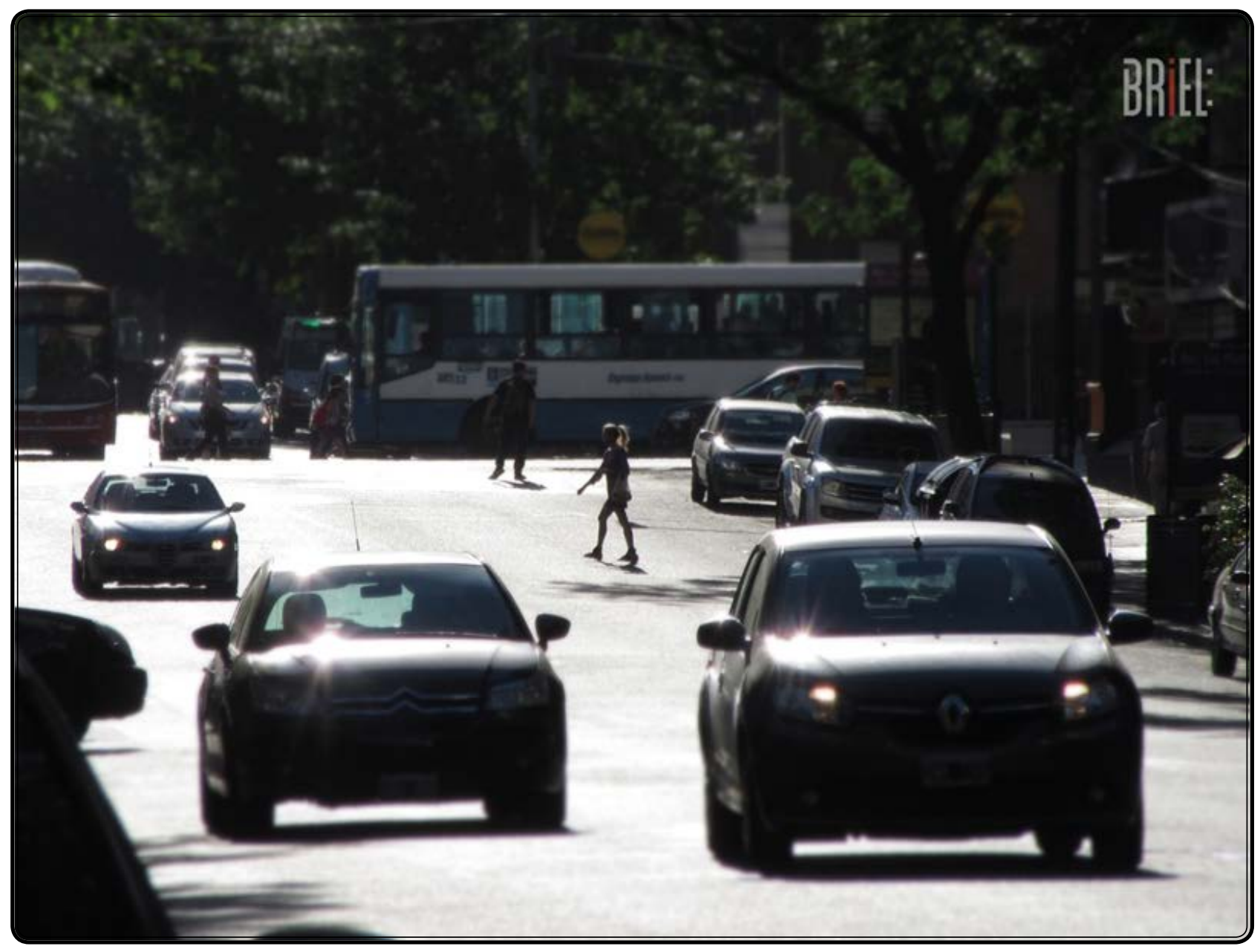

El movimiento, en movimiento. 